\title{
Exploration and Research on the Training Mode of Welding Technology and Automation Professionals Under the Background of Modern Apprenticeship
}

Hongli Miao

Gansu Vocational College of Architecture, Lanzhou 730050, Gansu Province

Research Project on Innovation and Entrepreneurship Education and Teaching Reform of Colleges and Universities in Gansu Province in 2018

Abstract: The realization of modern apprenticeship is a powerful way for vocational colleges to deepen the integration
of production and education, school-enterprise cooperation, further improve the school-enterprise cooperation education
mechanism, innovate the training model of technical and technical talents, and enhance the ability of students. This
article will discuss our school's welding technology and automation Under the background of the professional modern
apprenticeship pilot, the practice in the talent training model is briefly analyzed and discussed, in order to deepen the
school-enterprise collaborative education, and closely meet the needs of regional economic development. Keywords: Modern Apprenticeship; Welding Technology and Automation; Talent Training Model

The traditional welding technology and automation professional talent training model and content are mainly based on a certain traditional teaching training program to formulate a training plan, and a series of teaching rules and regulations to ensure the orderly progress of normal teaching activities, a fixed training plan and teaching management mode It is not conducive to the reform of teaching methods and teaching organization forms and the cultivation of innovative talents. In most vocational colleges, due to the constraints of actual conditions, the arrangement of teaching content emphasizes theory and practice, classroom and extracurricular, indoctrination and self-study, ignoring the systematic nature of engineering and its practical characteristics. For this reason, the welding technology and automation major of our school and Gansu Construction No. 1 Installation Engineering Co., Ltd. established the first modern apprenticeship "Yi' an Craftsman Class" in Gansu Province based on the requirements of welding operation technology positions.

\section{Work content}

\subsection{The talent training process combining deep chemical engineering}

Through the research on the actual needs of the job and the research on the growth law of technical and technical talents, the main direction of steel structure manufacturing and installation, pressure pipe installation and the Gansu First Installation Engineering Co., Ltd. jointly carried out a modern apprenticeship pilot program, and schools and enterprises jointly formulated talent training Plan, jointly build a talent training model and professional curriculum system, establish a school-enterprise mutual-employed and shared teaching team, jointly carry out the teaching and implementation of theoretical and practical courses in schools and enterprises, and jointly conduct courses, textbooks, and curriculum resource libraries The development of resources, joint exploration of apprenticeship assessment and evaluation methods that are compatible with modern apprenticeship, and a dual-primary sportsman mechanism led by the government and both schools and enterprises are educating subjects. The school undertakes systematic professional knowledge learning and skills training. The company provides job scenarios and work content that are directly in Copyright (C) 2020 Hongli Miao

doi: 10.18282/le.v9i7.1457

This is an open-access article distributed under the terms of the Creative Commons Attribution Non-Commercial License

(http://creativecommons.org/licenses/by-nc/4.0/), which permits unrestricted non-commercial use, distribution, and reproduction in any medium, provided the original work is properly cited. 
line with the job capabilities, and establishes a new type of master-apprentice relationship. Through the teacher and apprentices, the job skills training and development are carried out according to the training plan to truly realize the school Enterprise-integrated education. In particular, it is necessary to explore a talent training model suitable for the modern apprenticeship, and seek for an increase in the depth of the combination of work and study, so that students have strong vocational skills, can achieve "zero distance" employment, and have certain sustainable development capabilities.

\subsection{Establish a technology innovation ability training mechanism with students as the main body}

In the form of "school-in-plant", a "welding technology and automation professional training base" is jointly established in schools, schools and enterprises, and in the form of "factory-in-school", a "welding technology and automation professional production practice" "Training and Employment Base" and "Non-destructive Testing Training and Employment Base for Welding Technology and Automation Specialty", not only integrate superior resources of schools and enterprises, improve training conditions, but also provide a platform and support for college students' innovation. Instruct students (apprentices) to participate in actual enterprise projects, so that students understand the new knowledge and new technologies of the production line, deepen students' understanding of general standards and industry standards, take students as the main body of implementation of the work content, and take innovation as the main line to strengthen The ability of students to solve practical problems is a breakthrough to construct and explore the content and form of innovative welding professional practice teaching.

\subsection{Innovation of the practical teaching performance evaluation mechanism}

Professional teachers and part-time corporate teachers teach together, part of the core curriculum content adopts task-driven teaching mode, teaching is integrated, and the teaching process is implemented in accordance with the 6-step teaching method (consulting-decision-planning-implementation-inspection-evaluation), emphasizing task completion The evaluation of inspection courses allows students to participate in the evaluation of teaching performance, organizes corporate mentors, teachers' comments and student mutual evaluations. Process evaluation and result evaluation are combined, and the forms of evaluation and evaluation are diversified, which is highly innovative and comprehensive. Explore the content of flexible and flexible evaluation standards and focus on ability assessment; communication between teachers and students keeps pace with the times, and timely feedback.

\subsection{Strengthen job rotation teaching in off-campus practice teaching bases, and establish a cooperative mechanism of "production, study and research"}

In the form of "school-in-factory" and "school-in-factory", schools and enterprises jointly build a training base, which not only integrates the superior resources of schools and enterprises, improves training conditions, and promotes the construction of "production-learning-research" bases to advance the school Enterprise cooperation projects, deepen the cooperation of production, education and research, provide students with more practical learning opportunities, and follow the path of school-enterprise cooperation and benign interaction between production, education and research.

\subsection{Construction of a strong craftsman spirit and cultural atmosphere}

Through the welding profession, we regularly hire enterprise engineers, project managers and other engineering and technical talents to popularize welding engineering related application knowledge for professional teachers and students in the form of part-time, lectures or report meetings, and bring engineering examples, engineering culture and engineering atmosphere into the classroom The training room strives to create a practical environment and atmosphere in the school.

\section{Implementation effect}

\subsection{Improve the modern apprenticeship training system and curriculum system}

\subsection{1 “33324” modern apprenticeship talent training model}

Guided by the apprenticeship learning theory, the "33324" modern apprenticeship talent training model has been successfully constructed. Form a "three-dimensional management mechanism" of government, schools, and enterprises, 
build a "three-level curriculum system" of modularized courses, project-based content, and project-based jobs, and implement the "three-stage education" of school learning, rotation training, and internship Process" to realize the "four identity conversions" of students $\rightarrow$ apprentices $\rightarrow$ prospective employees $\rightarrow$ employees.

\subsubsection{Course system based on job standards}

Through enterprise research, analyze the main job positions corresponding to the welding profession, and determine the basic knowledge and ability course module, the job ability development course module, and the job ability improvement course module based on the principle of "what to learn and what is missing". New curriculum system.

\subsection{In-depth cooperation, win-win for the three parties}

The modern apprenticeship system is based on the needs of enterprises for employment, based on in-depth schoolenterprise cooperation, with student (apprenticeship) training as the core, complementary advantages, division of labor, and cooperation between schools and enterprises, which emphasizes both the systematic professional knowledge and the cultivation of comprehensive quality. The modern apprenticeship system of dual subjects has enhanced the integration of school-enterprise cooperation in running schools and is the best integration point for the common development of schools and enterprises. In-depth school-enterprise cooperation has promoted the development of school professional teachers' skill levels and teacher concepts, promoted the construction of teaching resources and training bases, and improved the school's ability to serve the society; the enterprise's talent needs have been precisely met. In addition, school teachers Participate in the actual engineering and scientific research projects of enterprises to help enterprises develop innovation and improve research capabilities; through the integration of enrollment and recruitment, the quality of employment of students is improved, the enthusiasm and initiative of learning are improved, and the practical ability is improved.

\subsection{Employment-oriented principle}

In the pilot enrollment work, the "single recruitment + recruitment" model is adopted. After students take the cultural course exam and enroll, the cooperative enterprise Gansu Yi'an Construction Technology Group Co., Ltd. assigns a human resources manager to preach to the students, introducing the company's situation and positions Set and post standards, organize students to participate in knowledge-based written examinations and comprehensive interviews, determine the enrollment list, and the school organizes schools, enterprises, and students to sign a tripartite agreement with apprentices, schools and enterprises. In the process of talent training, both schools and enterprises jointly formulate a training plan. The dedicated and combined team of teachers and corporate masters carry out the teaching of theoretical and practical courses, pay attention to rotation training, and strive to achieve "zero distance employment." Enterprises train employees according to their own needs, and can fully inspect students during student internships, select outstanding students, and truly achieve the goal of optimizing employment. For students, they can be familiar with the production organization and corporate culture of the enterprise, and quite a few apprentices are willing to stay in the apprenticeship pilot enterprises after graduation, and their employment prospects are relatively bright.

\section{Summary and outlook}

Through the modern apprenticeship pilot program, this major aims to participate in the whole process of vocational education talent training with cooperative enterprises, realize the connection of professional settings and industry needs, the connection of course content and professional standards, the connection of teaching and production processes, and improve the quality and targeting To improve the training ability and level of technical and technical personnel, and better serve the current economic and social development.

\subsection{Problems that may arise during the pilot process}

3.1.1 From the perspective of colleges, the quality of students is uneven, and the modern apprenticeship training target is higher than the ordinary three-year talent training target, which brings certain challenges to the teaching process of the colleges; in addition, due to the lack of effective Policy support, the actual interests of enterprises participating in school-enterprise cooperation and industry-university cooperation have not been effectively reflected, and they are not attractive. The enthusiasm of enterprises and industries to participate in school-enterprise cooperation is not strong; the 
system of modern apprenticeship is not fully guaranteed, and the concepts and teachers still need to be Promote.

3.1.2 From the perspective of the enterprise, the student training cycle is long, and the technical skills cannot meet the job requirements in a short time; at the practical level, how to deal with if the student quits halfway; whether the policy orientation and compensation guide the enterprise to accept apprentices in a timely manner Come now.

3.1.3 From the perspective of students, how to deal with the reduction in employment needs of enterprises in the later period, which cannot accept students in full, or the enterprises need to eliminate some students; after recruitment, some students are unwilling to work in the unit, how to deal with it.

\subsection{The next step and the main problems to be solved}

3.2.1 Innovative concepts, combining mixed ownership, mixed secondary colleges and modern apprenticeship talent training;

3.2.2. Innovate the management system, through organizational structure innovation, coordination, cross-teaching and scientific research for personnel training, through organizational system innovation, increase the participation and effectiveness of academic committees, professional steering committees, and project teams.

3.2.3. Innovate the system, continue to explore the issue of the credit system, how to adapt the flexible school system to the needs of the enterprise, and solve the problems of how to manage students in the enterprise, the formulation of the system, the length of service and the calculation of salary in the teaching management system.

3.2.4. Further improve the talent training mechanism and talent training model, increase the participation of enterprises in student innovation and entrepreneurship, optimize the teaching organization model; optimize the cooperation between teachers and masters.

3.2.5. Improve evaluation systems such as the elimination and supplementation system for students (apprentices), and the evaluation system for school-enterprise performance agreements.

\section{References}

1. Sun Peng. Modern apprenticeship to improve the level of talent training research and exploration [J]. China Training, 2015 (6).

2. Zhang Fakun. Research and Exploration on the Workpieces of Modern Apprenticeship Curriculum System in Business Higher Vocational Education [J]. Modern Vocational Education, 2019(2): 1-2.

3. To the Research Group of the Anhui Provincial Committee of the Zhi Gong Party. Current problems and suggestions for the implementation of modern apprenticeship [J]. Education and Occupation, 2018(14): 54-55.

4. Zhang Yu, Han Hailing. Analysis of the problems of modern apprenticeship and countermeasures[J]. Journal of Liaoning Technical College, 2018(2): 57-60.

5. Kong Shuiqing. The application of blended teaching in modern apprenticeship courses [J]. Modern Vocational Education, 2019(1): 168-169. 